Taksonomia 30

ISSN 1899-3192

Klasyfikacja i analiza danych - teoria i zastosowania

e-ISSN 2392-0041

\title{
Hanna Dudek
}

Szkoła Główna Gospodarstwa Wiejskiego w Warszawie

e-mail: hanna_dudek@sggw.pl

\section{ANALIZA WSKAŹNIKA POGEĘBIONEJ DEPRYWACJI MATERIALNEJ W REGIONACH UE ZA POMOCA REGRESJI DLA ZMIENNEJ FRAKCYJNEJ}

\section{ANALYSIS OF SEVERE MATERIAL DEPRIVATION RATE IN THE EU REGIONS USING FRACTIONAL REGRESSION}

DOI: $10.15611 /$ pn.2018.507.05

JEL Classification: C25, I32

Streszczenie: W pracy podjęto się weryfikacji adekwatności zastosowania modeli regresji dla zmiennej frakcyjnej (FRM) w analizie regionalnych poziomów wskaźnika pogłębionej deprywacji materialnej w UE. Wskaźnik ten jest odsetkiem osób wykazujących co najmniej 4 z 9 symptomów odnoszących się do braku możliwości zaspokojenia ze względów finansowych typowych potrzeb. Ponieważ wartości wskaźnika deprywacji należą do przedziału $[0,1]$, w pracy wykorzystano modele dla zmiennej frakcyjnej. Na podstawie wyników rozszerzonej wersji testu RESET stwierdzono, że - w przeciwieństwie do modeli liniowych - nie było podstaw do odrzucenia poprawności specyfikacji regresji dla zmiennej frakcyjnej. W konsekwencji tego efekty krańcowe określające zmiany warunkowej wartości oczekiwanej wskaźnika pogłębionej deprywacji materialnej były zależne od poziomów czynników uwzględnionych w charakterze zmiennych objaśniających.

Słowa kluczowe: deprywacja materialna, regresja dla zmiennej frakcyjnej, efekt krańcowy.

Summary: The paper deals with fractional regression models (FRM) applied to assess the impact of various socio-economic factors on severe material deprivation rates in the EU regions. The results of the extended RESET test indicate that linear model suffers from mis-specification, while there is no reason to reject the hypothesis about the adequacy of FRM. As a consequence, the marginal effects are dependent on the level of factors taken into account as explanatory variables in the FRM.

Keywords: material deprivation, fractional regression, marginal efects. 


\section{Wstęp}

W ostatnim okresie w literaturze przedmiotu podkreśla się, że ubóstwo stanowi zjawisko wielowymiarowe [Alkire i in. 2015; Asselin 2008]. Do jego identyfikacji wykorzystuje się różne czynniki, m.in. uwzględniające sytuację mieszkaniową oraz posiadanie dóbr trwałego użytku. Takie podejście jest stosowane obecnie m.in. w Unii Europejskiej, gdzie w celu oceny realizacji strategii Europa 2020 w zakresie zagrożenia ubóstwem lub wykluczeniem społecznym uwzględnia się trzy wskaźniki: wskaźnik ubóstwa relatywnego, wskaźnik osób żyjących w gospodarstwach domowych o bardzo niskiej intensywności pracy oraz wskaźnik pogłębionej deprywacji materialnej. Pierwszy ze wskaźników definiowany jest jako odsetek osób, których roczny ekwiwalentny dochód do dyspozycji jest niższy od granicy ubóstwa, przy czym granicę ustala się na poziomie $60 \%$ mediany rocznych ekwiwalentnych dochodów do dyspozycji w danym kraju. Porównywanie sytuacji bytowej w różnych krajach czy regionach UE na podstawie tego wskaźnika budzi jednak wątpliwości ze względu na fakt oddzielnego wyznaczania granicy ubóstwa w poszczególnych jednostkach terytorialnych. Drugim ze wskaźników jest odsetek osób żyjących w gospodarstwach domowych, w których osoby dorosłe w wieku produkcyjnym (18-59 lat) w minionym roku przepracowały mniej niż $20 \%$ ich całkowitego potencjału pracy. Jednak, jak wskazują eksperci z zakresu statystki społecznej, miernik ten stanowi miarę wykluczenia społecznego w obszarze rynku pracy i nie powinien być uwzględniany w analizie ubóstwa [Panek, Zwierzchowski 2016]. Trzeci ze wskaźników stanowi odsetek osób w gospodarstwach domowych wykazujących co najmniej 4 z 9 symptomów odnoszących się do braku możliwości zaspokojenia ze względów finansowych następujących potrzeb: 1) opłacenia tygodniowego wyjazdu wszystkich członków gospodarstwa domowego na wypoczynek raz w roku, 2) spożywania mięsa, ryb (lub wegetariańskiego odpowiednika) co drugi dzień, 3) ogrzewania mieszkania odpowiednio do potrzeb, 4) pokrycia niespodziewanego wydatku w wysokości odpowiadającej miesięcznej wartości granicy ubóstwa relatywnego, przyjętej w danym kraju, w roku poprzedzającym badanie, 5) terminowego regulowania opłat związanych z mieszkaniem, spłatą rat i kredytów, 6) posiadania telewizora kolorowego, 7) posiadania samochodu, 8) posiadania pralki, 9) posiadania telefonu.

Eksperci z zakresu statystyki społecznej podkreślają, że rozpatrywanie wskaźnika obejmującego różne symptomy deprywacji materialnej stanowi znaczący krok w kierunku pełniejszej analizy ubóstwa w ramach UE. Koncentrując się na braku możliwości zaspokojenia ze względów finansowych tych potrzeb, wskaźnik pogłębionej deprywacji materialnej umożliwia bardziej bezpośredni pomiar standardu życia ludności niż wskaźniki dochodowe [Panek, Zwierzchowski 2016]. Ponadto pomiar deprywacji materialnej, w przeciwieństwie do pomiaru ubóstwa dochodowego, odbywa się według podejścia absolutnego, a nie relatywnego, tzn. ocena sytuacji materialnej gospodarstw domowych nie opiera się na odniesieniu ich poziomu deprywacji do poziomu deprywacji innych gospodarstw domowych. Takie podejście zapewnia 
porównywalność sytuacji bytowej pomiędzy krajami UE i ich regionami. Dlatego też w pracy podjęto się analizy tego wskaźnika.

Literatura przedmiotu dotycząca identyfikacji makroczynników współzależnych ze wskaźnikiem pogłębionej deprywacji materialnej w UE jest bardzo uboga. Według najlepszej wiedzy autorki jedyne opracowania z tego zakresu stanowią prace [Calvert, Nolan 2012] oraz [Kis i in. 2015], w których wykorzystano modele liniowe oszacowane na podstawie danych na poziomie krajowym ${ }^{1}$. W niniejszym artykule rozpatrzono poziom regionalny wskaźników ubóstwa oraz modele dedykowane zmiennym objaśnianym przyjmującym wartości z przedziału $[0,1]$. Za cel pracy postawiono weryfikację statystyczną adekwatności zastosowania w analizie regionalnych wskaźników deprywacji materialnej modeli regresji dla zmiennej frakcyjnej oraz porównanie otrzymanych wyników z rezultatami uzyskanymi na podstawie modelu regresji liniowej.

\section{Charakterystyka danych empirycznych}

Zamierzeniem pracy była analiza danych dotyczących wskaźników ubóstwa w ujęciu regionalnym o jak najbardziej szczegółowym poziomie NUTS (fr. Nomenclature des Unités Territoriales Statistiques). System NUTS ma charakter hierarchiczny obejmujący poziom NUTS0, odzwierciedlający granice administracyjne krajów, poziom NUTS1, odnoszący się regionów dużych - od 3 do $7 \mathrm{mln}$ ludności, poziom NUTS2, dotyczący regionów średnich - od 800 tys. do 3 mln ludności, oraz poziom NUTS3, obejmujący regiony małe - od 150 do 800 tys. ludności. Przy czym, jeśli liczba ludności danego kraju nie przekracza dolnej granicy danego poziomu NUTS, to cały kraj jest traktowany jako jedna jednostka terytorialna na tym poziomie.

Niestety Eurostat, zamieszczając informacje na temat regionalnych wskaźników ubóstwa i wykluczenia społecznego, publikuje statystyki w sposób nieuporządkowany - dla niektórych regionów podając dane na poziomie NUTS2, dla innych zaś na poziomie NUTS1 lub NUTS0 [Eurostat 2017]. Dlatego też przeprowadzona w pracy analiza została dokonana na podstawie takich danych, jakie zostały udostępnione w bazie Eurostatu. W szczególności dla Belgii, Francji, Niemiec, Portugalii oraz Wielkiej Brytanii uwzględniono poziom NUTS0, dla Grecji, Holandii, Polski i Węgier - poziom NUTS1, dla pozostałych krajów - poziom NUTS2. Ograniczenia w kwestii dostępności danych statystycznych dotyczyły także cech rozpatrywanych

\footnotetext{
${ }^{1}$ Należy zaznaczyć, że obie wymienione prace są jedynie roboczymi opracowaniami badawczymi (odpowiednio: working paper i research note) i nie zostały opublikowane w liczących się czasopismach naukowych. Bardziej bogata literatura odnosi się natomiast do modelowania prawdopodobieństwa występowania deprywacji materialnej wśród gospodarstw domowych. W tego typu pracach, zawierających wyniki analiz wykonanych na podstawie łącznych mikrodanych $\mathrm{z}$ wielu państw UE, oprócz charakterystyk gospodarstw domowych, zwraca się też uwagę na rolę czynników na poziomie krajowym [Bárcena-Martín i in. 2014; Israel 2016)]. W niniejszej pracy jednak przedmiotem zainteresowania są makrodane na poziomie regionalnym.
} 
jako potencjalne determinanty ubóstwa w ujęciu regionalnym. Ostatecznie, biorąc pod uwagę sugestie płynące z przeglądu literatury przedmiotu [Bárcena-Martín i in. 2014; Israel 2016; Calvert, Nolan 2012; Kis i in. 2015] oraz kierując się względami merytorycznymi, rozważono m.in. następujące cechy: dochody do dyspozycji mieszkańców regionu per capita wyrażone w parytecie siły nabywczej, wskaźnik zagrożenia ubóstwem relatywnym (At-Risk Poverty Rate - ARPR), regionalny PKB per capita wyrażony w parytecie siły nabywczej (Purchasing Power Standard PPS) w tys. jednostek, stopę bezrobocia długoterminowego, tzn. procentowy udział osób bezrobotnych co najmniej 12 miesięcy w łącznej liczbie osób aktywnych zawodowo, wskaźnik osób żyjących w gospodarstwach domowych o bardzo niskiej intensywności pracy, udział osób przedwcześnie kończących kształcenie i szkolenie w populacji osób w wieku 18-24, udział osób z wykształceniem wyższym (na poziomie 5-8) w populacji osób w wieku 25-64. Ze względu na brak danych na temat wartości niektórych cech dla 2015 r., w analizie empirycznej wykorzystano dane z 2014 r.

\section{Modele regresji dla zmiennej frakcyjnej}

W opracowaniu podjęto się próby analizy wskaźnika pogłębionej deprywacji za pomocą modeli regresji dla zmiennej frakcyjnej (Fractional Response Model - FRM) zaproponowanych w pracy [Papke, Wooldridge 1996]. Modele te są szczególnie przydatne $\mathrm{w}$ analizie zmiennych opisujących frakcje, udziały, proporcje, stopy itp. FRM są modelami warunkowej wartości oczekiwanej zmiennej zależnej $y$. Oznaczając $E\left(y_{i} \mid \boldsymbol{x}_{i}\right)=\mu\left(\boldsymbol{x}_{i}\right)$, w celu zapewnienia by $\mu\left(\boldsymbol{x}_{i}\right) \in[0,1]$, w modelach regresji dla zmiennej frakcyjnej zakłada się, że:

$$
\mu\left(\boldsymbol{x}_{i}\right)=\mathrm{G}\left(\boldsymbol{x}_{i}^{\prime} \boldsymbol{\beta}\right),
$$

gdzie: $G(\cdot)$ - funkcja, $0<G(z)<1$ dla $z \in R, \boldsymbol{x}_{i}$ - wektor wartości zmiennych objaśniających dla $i$-tej jednostki, $\boldsymbol{\beta}$ - wektor parametrów podlegających estymacji.

W praktyce do opisu wartości (1) wykorzystuje się dystrybuantę rozkładu logistycznego, dystrybuantę standardowego rozkładu normalnego lub dystrybuanty rozkładów wartości ekstremalnych. Zestawienie odpowiednich wzorów zaprezentowano w tabeli 1 , przy czym warto odnotować, że funkcja $h$, będąca funkcją odwrotną do funkcji $G$, nazywana jest w literaturze przedmiotu funkcją wiążącą [Ramalho i in. 2011]. 
Tabela 1. Typowe specyfikacje dla warunkowej wartości oczekiwanej w modelach FRM

\begin{tabular}{|l|l|c|c|}
\hline Specyfikacja & \multicolumn{1}{|c|}{ Dystrybuanta rozkładu } & $\mathrm{G}\left(\mathbf{x}^{\prime} \boldsymbol{\beta}\right)=\mu$ & $h(\mu)=\mathbf{x} \boldsymbol{\beta}$ \\
\hline $\operatorname{logit}$ & logistycznego & $\frac{1}{1-\exp \left(-\mathbf{x}^{\prime} \boldsymbol{\beta}\right)}$ & $\ln \left(\frac{\mu}{1-\mu}\right)$ \\
\hline probit & $\begin{array}{l}\text { standardowego } \\
\text { normalnego }\end{array}$ & $\Phi\left(\mathbf{x}^{\prime} \boldsymbol{\beta}\right)$ & $\Phi^{-1}(\mu)$ \\
\hline $\log \log$ & wartości maksymalnych & $\exp \left(-\exp \left(-\mathbf{x}^{\prime} \boldsymbol{\beta}\right)\right)$ & $-\ln (-\ln (\mu))$ \\
\hline cloglog & wartości minimalnych & $1-\exp \left(-\exp \left(\mathbf{x}^{\prime} \boldsymbol{\beta}\right)\right)$ & $\ln (-\ln (1-\mu))$ \\
\hline
\end{tabular}

Źródło: opracowanie własne na podstawie [Ramalho i in. 2011].

Efekty krańcowe dla danej zmiennej $X_{j}$ są określone wzorem:

$$
\frac{\partial E\left(y_{i} \mid \boldsymbol{x}_{\boldsymbol{i}}\right)}{\partial x_{j i}}=\beta_{j} g\left(\boldsymbol{x}_{\boldsymbol{i}}^{\prime} \boldsymbol{\beta}\right)
$$

gdzie: $g\left(\boldsymbol{x}_{\boldsymbol{i}}^{\prime} \boldsymbol{\beta}\right)=\frac{\partial G\left(\boldsymbol{x}_{\boldsymbol{i}}^{\prime} \boldsymbol{\beta}\right)}{\partial\left(\boldsymbol{x}_{\boldsymbol{i}}^{\prime} \boldsymbol{\beta}\right)}, x_{j i}$ - wartość $j$-tej zmiennej objaśniającej dla $i$-tej jednostki, pozostałe oznaczenia - jak wcześniej objaśniono.

Kierunek zmian warunkowej wartości oczekiwanej zmiennej objaśnianej może być zatem oceniany na podstawie znaku parametru $\beta_{j}$ [Ramalho, Vidigal da Silva 2013].

Oszacowania wektora parametrów $\boldsymbol{\beta}$ w modelach regresji dla zmiennej frakcyjnej dokonano w pakiecie Stata, gdzie stosuje się do tego celu metodę quasi-wiarygodności. W metodzie tej nie jest wymagana wiedza na temat pełnego rozkładu analizowanych danych. Wykorzystuje się w niej jedynie informację o zależności opisującej warunkową wartość zmiennej zależnej y. Estymując wektor parametrów $\boldsymbol{\beta}$, rozpatruje się logarytm funkcji wiarygodności typu Bernoulliego:

$$
\ln L=\sum_{i=1}^{n}\left(y_{i} \ln G\left(\boldsymbol{x}_{i}^{\prime} \boldsymbol{\beta}\right)+\left(1-y_{i}\right) \ln \left(1-G\left(\boldsymbol{x}_{i}^{\prime} \boldsymbol{\beta}\right)\right)\right),
$$

gdzie: $n$ - liczba jednostek w próbie.

Jeśli funkcja $G$, opisująca warunkową wartość oczekiwaną, jest prawidłowo wyspecyfikowana, to estymatory parametrów otrzymane metodą quasi-wiarygodności są zgodne i asymptotycznie normalne. W celu weryfikacji poprawności specyfikacji funkcji $G$ Papke i Wooldridge [1996] proponują wykorzystanie rozszerzonej wersji testu RESET Ramseya [1969], rozpatrując zamiast (1) model²:

\footnotetext{
${ }^{2} \mathrm{~W}$ niniejszej pracy w celu przeprowadzenia rozszerzonego testu RESET wykorzystano procedurę linktest zaimplementowaną w programie Stata. Należy tu nadmienić, że wersji zastosowanej w pracy [Papke, Wooldridge 1996] oprócz kwadratu kombinacji liniowej x’b uwzględniono także jej sześcian.
} 


$$
\mu\left(\boldsymbol{x}_{i}\right)=G\left(\gamma\left(\boldsymbol{x}_{i}^{\prime} \boldsymbol{b}\right)+\delta\left(\boldsymbol{x}_{i}^{\prime} \boldsymbol{b}\right)^{2}\right),
$$

gdzie wektor $\boldsymbol{b}$ stanowi ocenę parametru $\boldsymbol{\beta}$ w modelu (1). Jeśli parametr $\delta$ istotnie różni się od zera, to należy odrzucić hipotezę o poprawności specyfikacji (1).

Porównania modeli z różnymi zestawami zmiennych objaśniających mogą zostać przeprowadzone na podstawie kryteriów informacyjnych, przy czym we wzorach definiujących AIC lub BIC zamiast logarytmu wiarygodności uwzględnia się logarytm quasi-wiarygodności. Do oceny dopasowania do danych empirycznych wykorzystuje się współczynnik pseudo- $\mathrm{R}^{2}$ [Ramalho, Vidigal da Silva 2013] ${ }^{3}$.

\section{Wyniki analizy}

Wstępna analiza danych ujawniła wystąpienie znacznego zróżnicowania regionalnych wskaźników pogłębionej deprywacji materialnej (Severe Material Deprivation - SMD) w UE. W szczególności we wszystkich regionach w Szwecji odnotowano wartości stopy SMD poniżej 2\%, natomiast w każdym z regionów Bułgarii udział populacji podlegających SMD wyniósł powyżej 30\%. W Polsce wartości regionalnej stopy SMD w 2014 r. kształtowały się na poziomie 9-13\%.

W celu analizy stochastycznej zależności między wskaźnikiem SMD a różnymi czynnikami oszacowano wiele modeli. Ze względu na znaczną korelację pomiędzy niektórymi z tych czynników ${ }^{4}$ rozpatrzono kilka zestawów zmiennych objaśniających. W pracy zeprezentowano wyniki estymacji dwóch modeli charakteryzujących się najlepszymi wartościami kryterium informacyjnego AIC oraz współczynnika pseudo- $\mathrm{R}^{2}$. W modelu 1 uwzględniono zmienne dotyczące sytuacji dochodowej ludności: logarytm naturalny dochodów mieszkańców regionu per capita wyrażonych w PPS oraz wskaźnik zagrożenia ubóstwem relatywnym ARPR. Rozpatrzono modele dla zmiennej frakcyjnej z czterema różnymi funkcjami wiążącymi oraz model liniowy. Wyniki zamieszczono w tabeli 2.

Wyniki testu RESET wskazują, że nie było podstaw do odrzucenia poprawności specyfikacji wszystkich modeli dla zmiennej frakcyjnej, natomiast zdecydowanie powinno się odrzucić postać liniową modelu. Analizując łącznie rezultaty tego testu, kryterium $A I C$ oraz współczynnik pseudo- $\mathrm{R}^{2}$, należy odnotować, że logit stanowi tu najbardziej adekwatną postać modelu. Znaki oszacowań parametrów informują jedynie o kierunku zmian zmiennej objaśnianej, czyli wzrost dochodów ludności wiązał się ze spadkiem wartości oczekiwanej wskaźnika deprywacji, natomiast wzrost odsetka osób zagrożonych relatywnym ubóstwem dochodowym - ze zwiększeniem wskaźnika SMD. Dokładniejszych informacji dostarczają wartości efektów krań-

${ }^{3}$ Współczynnik pseudo- $\mathrm{R}^{2}$ jest równy kwadratowi współczynnika korelacji Pearsona między zmienną $y$ a warunkową wartością oczekiwaną tej zmiennej [Ramalho, Vidigal da Silva 2013].

${ }^{4}$ M.in. wartość współczynnika korelacji Pearsona między ln dochodów do dyspozycji mieszkańców regionu (per capita) a ln regionalnego PKB (per capita) wyniosła 0,908. 
cowych wyznaczonych dla konkretnych wartości zmiennych objaśniających (por. wzór (2)). W tabeli 3 zamieszczono wyniki dla kwartyli rozkładu danej zmiennej, przyjmując wartość pozostałej zmiennej na poziomie mediany.

Tabela 2. Wyniki estymacji modelu $1 \mathrm{z}$ różnymi postaciami funkcyjnymi

\begin{tabular}{|c|c|c|c|c|c|}
\hline \multirow{2}{*}{ Zmienne } & \multicolumn{4}{|c|}{ Model dla zmiennej frakcyjnej z funkcją: } & \multirow{2}{*}{$\begin{array}{l}\text { Model } \\
\text { liniowy }\end{array}$} \\
\hline & logit & probit & Loglog & cloglog & \\
\hline Ln dochodów & $\begin{array}{c}-2,146^{* * * *} \\
(0,323)\end{array}$ & $\begin{array}{c}-1,147 \text { *** } \\
(0,177)\end{array}$ & $\begin{array}{c}-0,902 * * * \\
(0,156)\end{array}$ & $\begin{array}{c}-1,926^{* * *} \\
(0,282)\end{array}$ & $\begin{array}{c}-0,229 * * * \\
(0,046)\end{array}$ \\
\hline Wskaźnik ARPR & $\begin{array}{c}2,135^{* *} \\
(1,116)\end{array}$ & $\begin{array}{l}1,072^{*} \\
(0,628)\end{array}$ & $\begin{array}{c}0,797 \\
(0,536)\end{array}$ & $\begin{array}{c}2,048 * * \\
(0,996)\end{array}$ & $\begin{array}{c}0,181 \\
(0,166)\end{array}$ \\
\hline Stała & $\begin{array}{c}17,658^{* * * *} \\
(3,096)\end{array}$ & $\begin{array}{c}9,367 * * * \\
(1,712)\end{array}$ & $\begin{array}{c}7,565 * * * \\
(1,524)\end{array}$ & $\begin{array}{c}15,532 * * * \\
(2,687)\end{array}$ & $\begin{array}{c}2,246^{* * *} \\
(0,456)\end{array}$ \\
\hline \multicolumn{6}{|c|}{ Statystyki oceniające model: } \\
\hline Kryterium informacyjne AIC & 0,489 & 0,490 & 0,491 & 0,490 & - \\
\hline Współczynnik pseudo-R ${ }^{2}$ & 0,738 & 0,742 & 0,740 & 0,729 & 0,676 \\
\hline Wartość $p$ w teście RESET ${ }^{\mathrm{a}}$ & 0,908 & 0,440 & 0,392 & 0,726 & $\begin{array}{c}\text { mniejsza } \\
\text { niż } 0,01\end{array}$ \\
\hline
\end{tabular}

W nawiasach podano standardowe błędy szacunku parametrów skorygowane ze względu na pogrupowanie obserwacji w $\mathrm{krajach}^{5}, *$ oznacza istotność na poziomie $0,1, * *$ na poziomie 0,05 oraz *** na poziomie 0,$01 ;{ }^{a}$ Wartość $p$ w odnosi się do weryfikacji istotności parametru $\delta$ we wzorze (4).

Źródło: opracowanie własne na podstawie danych Eurostatu.

Tabela 3. Efekty krańcowe wyznaczone na podstawie oszacowań modelu 1 dla funkcji logit

\begin{tabular}{|c|c|c|c|}
\hline \multicolumn{1}{|c|}{ Zmienne } & Pierwszy kwartyl & Mediana & Trzeci kwartyl \\
\hline \multirow{2}{*}{ Ln dochodów } & $-0,225^{* * *}$ & $-0,151^{* * *}$ & $-0,110^{* * *}$ \\
& $(0,031)$ & $(0,014)$ & $(0,095)$ \\
\hline \multirow{2}{*}{ Wskaźnik ARPR } & $0,140^{*}$ & $0,150^{*}$ & $0,166^{*}$ \\
& $(0,076)$ & $(0,086)$ & $(0,103)$ \\
\hline
\end{tabular}

W nawiasach podano standardowe błędy szacunku parametrów wyznaczone metodą delty.

Źródło: opracowanie własne w programie Stata.

Z informacji przedstawionych w tabeli 3 wynika, że przy ustaleniu wartości wskaźnika ARPR na poziomie mediany, wzrostowi dochodów do dyspozycji mieszkańców regionu per capita o 1\% towarzyszył spadek stopy pogłębionej deprywacji materialnej odpowiednio o 0,225 punktu procentowego, gdy logarytm naturalny dochodów był na poziomie pierwszego kwartyla, o 0,151 punktu procentowego dla logarytmu dochodów na poziomie mediany oraz o 0,110 punktu procentowego dla

${ }^{5}$ Wykorzystano opcję „clustered robust standard errors” w programie Stata. 
logarytmu dochodów na poziomie trzeciego kwartyla. Biorąc pod uwagę zmiany wskaźnika ARPR, przy stałej wartości logarytmu naturalnego dochodów na poziomie mediany, wzrostowi stopy zagrożenia ubóstwem relatywnym o 1 punkt procentowy odpowiadało zwiększenie stopy SMD o 0,140 punktu procentowego, gdy wskaźnik ARPR był na poziomie pierwszego kwartyla, o 0,150 punktu procentowego dla mediany wskaźnika ARPR oraz o 0,166 punktu procentowego, jeśli wskaźnik ARPR był na poziomie trzeciego kwartyla ${ }^{6}$.

W tabeli 4 zamieszczono wyniki estymacji modeli uwzględniających jako zmienne objaśniające regionalny PKB per capita wyrażony PPS, udział osób przedwcześnie kończących kształcenie i szkolenie w populacji młodzieży w wieku 18-24 oraz stopę bezrobocia długoterminowego.

Tabela 4. Wyniki estymacji modelu $2 \mathrm{z}$ różnymi postaciami funkcyjnymi

\begin{tabular}{|c|c|c|c|c|c|}
\hline \multirow{2}{*}{ Zmienne } & \multicolumn{4}{|c|}{ Model dla zmiennej frakcyjnej z funkcją: } & \multirow{2}{*}{$\begin{array}{l}\text { Model } \\
\text { liniowy }\end{array}$} \\
\hline & logit & probit & $\log \log$ & cloglog & \\
\hline In $\mathrm{PKB}$ per capita & $\begin{array}{c}-1,724 * * * \\
(0,197)\end{array}$ & $\begin{array}{c}-0,910 * * * \\
(0,107)\end{array}$ & $\begin{array}{c}-0,707 * * * \\
(0,093)\end{array}$ & $\begin{array}{c}-1,569^{* * *} \\
(0,178)\end{array}$ & $\begin{array}{c}-0,180^{* * *} \\
(0,033)\end{array}$ \\
\hline $\begin{array}{l}\text { Odsetek osób przedwcz. } \\
\text { kończ. kształcenie }\end{array}$ & $\begin{array}{c}6,232 * * * \\
(1,970) \\
\end{array}$ & $\begin{array}{c}3,371 * * * \\
(1,060)\end{array}$ & $\begin{array}{c}2,688 * * * \\
(0,877) \\
\end{array}$ & $\begin{array}{c}5,578 * * * \\
(1,171) \\
\end{array}$ & $\begin{array}{c}-0,644 * * * \\
(0,202) \\
\end{array}$ \\
\hline $\begin{array}{l}\text { Stopa bezr. dł.*odsetek } \\
\text { osób przedw. k. kształc. }\end{array}$ & $\begin{array}{c}-57,374 * * * \\
(16,023) \\
\end{array}$ & $\begin{array}{c}-30,770^{* * *} \\
(9,080)\end{array}$ & $\begin{array}{c}-24,291 * * * \\
(7,813)\end{array}$ & $\begin{array}{c}-52,157 * * * \\
(14,010) \\
\end{array}$ & $\begin{array}{c}-5,490 * * * \\
(1,806) \\
\end{array}$ \\
\hline $\begin{array}{l}\text { Stopa bezrobocia } \\
\text { dhugoterminowego }\end{array}$ & $\begin{array}{c}9,258 * * * \\
(3,363)\end{array}$ & $\begin{array}{c}4,805^{* * *} \\
(1,952)\end{array}$ & $\begin{array}{l}3,657^{* *} \\
(1,699)\end{array}$ & $\begin{array}{c}8,634 * * * \\
(2,945)\end{array}$ & $\begin{array}{c}0,657 \\
(0,423)\end{array}$ \\
\hline Stała & $\begin{array}{c}2,270 * * * \\
(0,789) \\
\end{array}$ & $\begin{array}{c}1,010 * * * \\
(0,437) \\
\end{array}$ & $\begin{array}{c}1,035 * * * \\
(0,375) \\
\end{array}$ & $\begin{array}{c}1,801 * * * \\
(0,702)\end{array}$ & $\begin{array}{c}0,605 * * * \\
(0,123) \\
\end{array}$ \\
\hline \multicolumn{6}{|c|}{ Statystyki oceniające model: } \\
\hline Kryterium AIC & 0,517 & 0,517 & 0,518 & 0,517 & - \\
\hline Współczynnik pseudo- $\mathrm{R}^{2}$ & 0,733 & 0,739 & 0,739 & 0,725 & 0,670 \\
\hline $\begin{array}{l}\text { Wartość } p \text { w teście } \\
\text { RESET }\end{array}$ & 0,904 & 0,749 & 0,374 & 0,697 & $\begin{array}{c}\text { mniejsza } \\
\text { niż } 0,01\end{array}$ \\
\hline
\end{tabular}

Źródło: opracowanie własne na podstawie danych Eurostatu.

Podobnie jak w modelu 1, największa wartość $p$ w teście RESET odnosi się do modelu z funkcją wiążącą logit, najmniejsza zaś - do modelu liniowego. W tabeli 5 zamieszczono wyniki dotyczące efektów marginalnych wyznaczonych dla kwartyli rozkładu danej zmiennej, przyjmując wartości pozostałych zmiennych objaśniających na poziomie mediany.

${ }^{6}$ Interpretując wyniki, uwzględniono, że zarówno wartości wskaźnika SMD, jak i ARPR zawierały się w przedziale $[0,1]$ oraz w charakterze zmiennej objaśniającej wykorzystano zlogarytmowane wartości dochodów. 
Tabela 5. Efekty krańcowe wyznaczone na podstawie oszacowań modelu 2 dla funkcji logit

\begin{tabular}{|l|c|c|c|}
\hline \multicolumn{1}{|c|}{ Zmienne } & Pierwszy kwartyl & Mediana & Trzeci kwartyl \\
\hline In PKB per capita & $-0,155^{* * *}$ & $-0,125^{* * *}$ & $-0,088^{* * *}$ \\
& $(0,025)$ & $(0,014)$ & $(0,008)$ \\
\hline Odsetek osób przedwcześnie & $0,255^{* * *}$ & $0,281^{* * *}$ & $0,347^{* *}$ \\
kończących kształcenie & $(0,081)$ & $(0,099)$ & $(0,147)$ \\
\hline \multirow{2}{*}{ Stopa bezrobocia długoterminowego } & $0,245^{* *}$ & $0,261^{*}$ & $0,300^{*}$ \\
& $(0,125)$ & $(0,142)$ & $(0,185)$ \\
\hline
\end{tabular}

W nawiasach podano standardowe błędy szacunku parametrów wyznaczone metodą delty.

Źródło: opracowanie własne w programie Stata.

Na podstawie informacji przedstawionych w tabeli 5 można ocenić wpływ jednostkowego zwiększenia się poszczególnych cech uwzględnionych w modelu na wartość wskaźnika SMD, przy założeniu ceteris paribus. W szczególności, uwzględniając wartości stopy bezrobocia długoterminowego oraz odsetka osób przedwcześnie kończących edukację na poziomie mediany, wzrost regionalnego PKB per capita o $1 \%$ wiązał się ze spadkiem stopy pogłębionej deprywacji materialnej odpowiednio:

- o 0,155 punktu procentowego, gdy logarytm naturalny regionalnego PKB per capita był na poziomie pierwszego kwartyla,

- o 0,125 punktu procentowego, gdy logarytm naturalny regionalnego PKB per capita był na poziomie mediany,

- o 0,088 punktu procentowego, gdy logarytm naturalny regionalnego PKB per capita był na poziomie trzeciego kwartyla.

Analogicznie, biorąc pod uwagę wartości pozostałych zmiennych na poziomie mediany, wzrostowi odsetka osób przedwcześnie kończących edukację o 1 punkt procentowy towarzyszył wzrost oczekiwanej stopy SMD odpowiednio dla poszczególnych kwartyli o $0,255,0,281$ oraz 0,347 punktu procentowego, natomiast ze zwiększeniem stopy bezrobocia długoterminowego o 1 punkt procentowy wiązał się wzrost oczekiwanej wartości wskaźnika pogłębionej deprywacji materialnej - stosownie o $0,245,0,261$ oraz 0,300 punktu procentowego.

Należy podkreślić, że rozpatrując modele $\mathrm{z}$ innymi niż uwzględnione w modelach 1 i 2 zestawami zmiennych objaśniających, uzyskano podobne rezultaty wskazujące na brak podstaw do odrzucenia poprawności specyfikacji modeli dla zmiennej frakcyjnej, natomiast odrzucono możliwość zastosowania modelu liniowego.

\section{Podsumowanie}

Stopa pogłębionej deprywacji materialnej jest jednym ze wskaźników wykorzystywanych w analizach zagrożenia ubóstwem lub wykluczeniem społecznym mieszkańców regionów UE. Wskaźnik ten dotyczy braku możliwości zaspokojenia ze względów finansowych 4 z 9 potrzeb uznanych przez unijnych ekspertów za typowe 
dla osób z UE. Z uwagi na fakt, że wartości rozpatrywanego wskaźnika należą do przedziału $[0,1]$, w pracy wykorzystano modele dla zmiennej frakcyjnej. W przeciwieństwie do modeli liniowych stwierdzono, że nie było podstaw do odrzucenia poprawności specyfikacji tych modeli. Skutkiem tego efekty krańcowe zależały od poziomów czynników uwzględnionych w charakterze zmiennych objaśniających. Wynik ten stanowi pewien wkład w literaturę, gdzie dotychczas stosowano do opisu wskaźnika SMD jedynie modele liniowe.

Pewne ograniczenie przeprowadzonej analizy stanowiła dostępność danych publikowanych przez Eurostat. W celu uzyskania brakujących informacji na temat niektórych regionów NUTS2, w przyszłości warto wykorzystać źródłowe mikrodane EU-SILC, na podstawie których wyznaczane są wskaźniki regionalne. Dysponowanie dokładniejszymi danymi umożliwiłoby przeprowadzenie pogłębionej analizy czynników mających wpływ na kształtowanie się wskaźników pogłębionej deprywacji materialnej w regionach UE.

\section{Literatura}

Alkire S., Foster J.E., Seth S., Santos M.E., Roche J.M., Ballon P., 2015, Multidimensional Poverty Measurement and Analysis, Oxford University Press, Oxford.

Asselin L.-M., 2008, Analysis of Multidimensional Poverty. Theory and Case Studies, Springer, Ottawa. Bárcena-Martín E., Lacomba B., Moro-Egido A.I., Pérez-Moreno S., 2014, Country differences in material deprivation in Europe, Review of Income and Wealth, vol. 60, s. 802-820.

Calvert E., Nolan B., 2012, Material deprivation in Europe, GINI Discussion Paper, no. 68.

Eurostat, 2017, http://appsso.eurostat.ec.europa.eu/nui/show.do?dataset=ilc_mddd21\&lang=en (3.10. 2017).

Israel S., 2016, More than cash: societal influences on the risk of material deprivation, Social Indicators Research, vol. 129(2), s. 619-637.

Kis A., Özdemir E., Ward T., 2015, Micro and macro drivers of material deprivation rates, Research note of European Commission, no. 7.

Panek T., Zwierzchowski J., 2016, Ubóstwo w krajach Unii Europejskiej, Ekonomista, nr 2, s. 180-199. Papke L.E., Wooldridge J.M., 1996, Econometric methods for fractional response variables with an application to 401(K) plan participation rate, Journal of Applied Econometrics, vol. 11, s. 619-632.

Ramalho E.A., Ramalho J.J.S., Murteira J.M.R., 2011, Alternative estimating and testing empirical strategies for fractional regression models, Journal of Economic Surveys, vol. 25(1), s. 19-68.

Ramalho J.J.S., Silva J.V., 2013, Functional form issues in the regression analysis of financial leverage ratios, Empirical Economics, vol. 44(2), s. 799-831.

Ramsey J.B., 1969, Tests for specification errors in classical linear least squares regression analysis, Journal of the Royal Statistical Society, series B, vol. 31, s. 350-371. 